\title{
Cross-linked dry bonding: A new etch-and-rinse technique
}

\author{
Jianfeng Zhou ${ }^{a}$, Ayaka Chiba ${ }^{b}$, Debora L.S. Scheffel ${ }^{c}$, Josimeri Hebling ${ }^{c}$, \\ Kelli Agee ${ }^{d}$, Junji Tagami ${ }^{b}$, Jianquo Tan ${ }^{a}$, Dalia Abuelenain ${ }^{e}$, \\ Manar Abu Nawareg ${ }^{e}$, Ali H. Hassan ${ }^{e}$, Lorenzo Breschi ${ }^{f}$, Franklin R. Tay ${ }^{g}$, \\ David H. Pashley ${ }^{d, *}$ \\ a Department of Prosthodontics, Peking University School and Hospital of Stomatology, Beijing, PR China \\ b Department of Cariology and Operative Dentistry, Graduate School of Medical and Dental Sciences, Tokyo Medical \\ and Dental University, Tokyo, Japan \\ c Department of Orthodontics and Pediatric Dentistry, Universidade Estadual Paulista-UNESP, Araraquara Dental \\ School, Araraquara, Sao Paulo, Brazil \\ d Department of Oral Biology, The Dental College of Georgia, Augusta University, Augusta, GA, USA \\ e Faculty of Dentistry, King Abdulaziz University, Jeddah, Saudi Arabia \\ ${ }^{\mathrm{f}}$ Department of Biomedical and Neuromotor Sciences DIBINEM, University of Bologna and IGM-CNR Unit of \\ Bologna, Bologna, Italy \\ g Department of Endodontics, The Dental College of Georgia, Augusta University, Augusta, GA, USA
}

\section{A R T I C L E I N F O}

Article history:

Received 2 October 2015

Received in revised form

16 March 2016

Accepted 22 June 2016

\section{Keywords:}

Wet bonding

Dry bonding

Dentin

Dentin bonding

Dentin stiffness

Cross-linking

Grape seed extract

Collagen degradation

Bond strength

\begin{abstract}
A B S T R A C T
Objective. To determine if acid-etched, cross-linked dentin can be dehydrated without lowering bond strength below that of cross-linked wet-bonded dentin in vitro.

Methods. Using extracted human third molars, control acid-etched dentin was bonded with Single Bond Plus, using either the wet- or dry-bonding technique. Experimental acid-etched dentin was treated with 5 mass\% grape seed extract (GSE) in different solvents for $1 \mathrm{~min}$ before undergoing wet us dry resin-dentin bonding with Single Bond Plus. Completely demineralized dentin beams were treated with $5 \%$ GSE for 0,1 or $10 \mathrm{~min}$, before measuring stiffness by 3-point flexure. Other completely demineralized beams were treated similarly and then incubated in buffer for 1 week to measure the collagen solubilization by endogenous dentin proteases.

Results. $24 \mathrm{~h}$ microtensile bond strengths ( $\mu \mathrm{TBS}$ ) in wet and dry controls were $53.5 \pm 3.6$ and $9.4 \pm 1.8 \mathrm{MPa}$, respectively $(p<0.05)$. $5 \%$ GSE in water gave $\mu \mathrm{TBS}$ of $53.7 \pm 3.4$ and $39.1 \pm 9.7 \mathrm{MPa}(p<0.05)$, respectively, while $5 \%$ GSE in ethanol gave $\mu$ TBS of $51.2 \pm 2.3$ and $35.3 \pm 2.0 \mathrm{MPa}(p<0.05) .5 \% \mathrm{GSE}$ in $5 \% \mathrm{EtOH} / 95 \%$ water gave wet and dry $\mu \mathrm{TBS}$ of $53.0 \pm 2.3$ and $55.7 \pm 5.1 \mathrm{MPa}(p>0.05)$. Cross-linking demineralized dentin with $5 \%$ GSE increased stiffness of dentin and decreased collagen degradation $(p<0.05)$.

Significance. $5 \%$ GSE pretreatment of acid-etched dentin for $1 \mathrm{~min}$ permits the dentin to be completely air-dried without lowering bond strength.
\end{abstract}

(c) 2016 The Academy of Dental Materials. Published by Elsevier Ltd. All rights reserved.

\footnotetext{
* Corresponding author at: Department of Oral Biology, The Dental College of Georgia, Augusta University, Augusta, GA 30912-1129, USA. Tel.: +1 7067212031.

E-mail address: DPASHLEY@gru.edu (D.H. Pashley).

http://dx.doi.org/10.1016/j.dental.2016.06.014

0109-5641/@ 2016 The Academy of Dental Materials. Published by Elsevier Ltd. All rights reserved.
} 


\section{Introduction}

Water is one of the strongest hydrogen bonding solvents known, and has a Hoy's solubility parameter for hydrogen bonding cohesive forces $\left(\delta_{h}\right)$ of $40.4\left(\mathrm{~J} / \mathrm{cm}^{2}\right)^{1 / 2}$ [1]. The intrinsic tendency of collagen peptides to form interpeptide $\mathrm{H}$-bonds with each other in the absence of water is $14.8\left(\mathrm{~J} / \mathrm{cm}^{2}\right)^{1 / 2}$ [2]. Such interpeptide hydrogen bonding cannot occur in the presence of water. That is, water molecules cluster around carbonyl oxygens and amide hydrogens in peptide bonds, which prevent direct hydrogen bonding between neighboring collagen peptides. The stiffness of demineralized dentin matrices is inversely related to the solubility parameter for hydrogen bonding cohesive forces of polar solvents [3,4]. Water is not only a solvent, but participates in many protein-water-coupled phenomena [5].

During cavity preparations, dentists expose mineralized tooth dentin that has a modulus of elasticity of $20,000 \mathrm{MPa}$ [6]. To create microporosities in that dentin for resin-infiltration, they strip away the apatite crystallites in the mineralized matrix by acid-etching dentin, which solubilizes those crystallites to a depth of $10 \mu \mathrm{m}$ [7]. After water rinsing to extract the residual acid and solubilized minerals, the exposed demineralized collagen fibrils have a modulus of elasticity of only 3-5 MPa [2]. As long as these collagen fibrils are suspended in water, they are very pliable. However, if that water is removed by evaporation or dehydrating solvents, the compliant collagen fibrils rapidly form interpeptide hydrogen bonds with their nearest neighbors. When this occurs, the $50-100 \mathrm{~nm}$ diameter collagen fibrils hydrogen bond to each other to form an impermeable membrane-like structure that prevents the permeation of solvated adhesive monomers around collagen fibrils $[2,8]$. This results in resin-dentin bond values of only $10 \mathrm{MPa}$. To avoid drying-induced shrinkage, and to create higher resin-dentin bond strengths, Kanca developed what is called the "wet-bonding technique" [9-11], where demineralized dentin is allowed to float in $70 \%$ water [7] during the monomer infiltration phase of dentin bonding. That bonding technique leaves far too much residual water in resin-dentin bonds [12,13], and provides hydrolytic fuel for the endogenous proteases of dentin matrices which slowly hydrolyze collagen fibrils in resin-bonded dentin, resulting in poor durability of resin-dentin bonds [7]. The goal of resin infiltration during dentin bonding is to replace all of the 70 vol\% rinse water with 70 vol\% adhesive monomers [7]. However, dimethacrylates such as triethylene glycol dimethacrylate are almost insoluble in water. They undergo phase changes from monomers in solution, to monomers in resin globules suspended in water [14-16]. Because these resin globules are too large to permeate through the $20 \mathrm{~nm}$ wide interfibrillar spaces, this results in significant amounts of collagen fibrils in hybrid layers being surrounded by water instead of polymerized resin [12]. To prevent phase changes, most manufacturers have added $30-50$ vol\% of water-soluble monomethacrylates such as 2hydroxyethyl methacrylate (HEMA) to both scavenge residual water, and act as a solvent for dimethacrylates. However, monomethacrylates cannot produce strong cross-linked polymers. Rather, HEMA-rich polymers form elastomers that are not cross-linked. They are weak polymers which attract water to themselves that plasticizes their mechanical properties [17].

The authors propose to eliminate these problems by making the following modifications to the "wet-bonding technique". After rinsing away the unreacted acid and solubilized minerals, collagen fibrils suspended in water would be crosslinked by grape seed extract (GSE) [18-21] for $60 \mathrm{~s}$. This agent is meant to be illustrative of cross-linking agents in general (i.e. carbodiimide, glutaraldehyde, etc.) $[22,23]$. The excess, unreacted cross-linker would then be rinsed away with water and the stiffened collagen fibril matrix air dried. There is an inverse relationship between shrinkage and stiffness of demineralized dentin $[24,25]$. That is, as stiffness increases, shrinkage decreases, allowing the individual collagen fibrils to be separated from each other by air.

The other problem is how to remove excess water. The vapor pressure of pure rinse water is much higher than it is after adding water-soluble adhesive monomers, which lower the vapor pressure of water (Raoult's Law) [26,27]. By evaporating the rinse water before adding primers or adhesives, it is possible to remove nearly all the rinse water added to dentin within $30 \mathrm{~s}$ using a strong, continuous air blast. In the absence of water, adhesive formulations free of HEMA and made entirely of dimethacrylates can be added to dry acid-etched, cross-linked dentin matrix [28]. The end result should be a hybrid layer free of residual water and filled with dimethacrylates that absorb little water [24]. Tay et al. [28] reported that ethanol-solubilized BisGMA could infiltrate ethanol-rinsed, acid-etched dentin using a new bonding technique called "ethanol wet-bonding" [2,29-31]. That bonding technique removed residual water by chemical dehydration with ethanol, an excellent solvent for dimethacrylates.

The purpose of the present work was to test three null hypotheses: (1) that there is no difference in the $24 \mathrm{~h}$ microtensile bond strengths ( $\mu$ TBS) of acid-etched dentin bonded to non-cross-linked wet us dry specimens; (2) that there is no difference in the $24 \mathrm{~h} \mu \mathrm{TBS}$ of acid-etched dentin bonded to GSE cross-linked dry us GSE cross-linked wet specimens; (3) that there is no difference in the $24 \mathrm{~h} \mu \mathrm{TBS}$ of acid-etched dentin bonded to non-crosslinked wet-bonded us GSE cross-linked wet-bonded dentin.

\section{Materials and methods}

\subsection{Teeth used for resin-dentin bonding}

Thirty-two un-erupted human third molars were obtained from young (18-22 year old) patients in the Oral Surgery Clinics of The Dental College of Georgia at Augusta University with signed informed consent. They were stored in water containing $0.02 \%$ sodium azide as an antimicrobial, at $4{ }^{\circ} \mathrm{C}$ for less than 1 month before use.

\subsection{Cross-linking agent}

Proanthocyanidin was a gift from Dr. A. Bedran-Russo, who purchased it as Mega Natura-BP, from Polyphenolics, Madera, CA, USA. It was extracted from Vitis vinefera grapes and has been reported to contain 79.6 mass\% total polyphenols [32]. It 
was dissolved in water, ethanol or 5\% ethanol/95\% water at 5 mass $\%$.

\subsection{Bonding procedures}

Occlusal enamel and superficial dentin were removed from the 32 extracted teeth using a Buehler diamond blade saw (Buehler Ltd., Lake Bluff, IL, USA) with copious water cooling. Then, the flat exposed mid-coronal dentin was sanded with wet 180-grit silicon carbide paper to create a standard smear layer $[33,34]$. The flat occlusal dentin surface of all teeth were acid-etched for $15 \mathrm{~s}$ with $37 \%$ phosphoric acid gel (3M ESPE, St. Paul, MN, USA). All etched teeth were rinsed with water for $60 \mathrm{~s}$ to remove unreacted acid and to extract solubilized mineral. In experimental specimens, the acid-etched dentin surface was treated for $60 \mathrm{~s}$ with one of the following GSE experimental cross-linking primers: 5 mass $\%$ GSE in water ( $\mathrm{pH}$ 3.26), 5 mass\% GSE in ethanol ( $\mathrm{pH} 4.17$ ), or 5 mass $\%$ GSE in 5\% ethanol/95\% water ( $\mathrm{pH} 3.48$ ). Cross-linking was then terminated by rinsing dentin surface with air-water spray for $10 \mathrm{~s}$.

Specimens in the wet-bonded control group were not pretreated with GSE, and bonded using the wet-bonding technique. They were left visibly moist when bonding with Single Bond Plus (3M ESPE). Bonding was accomplished by application of two separate layers of solvated adhesive, followed by evaporation of the solvent for $5 \mathrm{~s}$ and light-curing for $40 \mathrm{~s}$ at $600 \mathrm{~mW} / \mathrm{cm}^{2}$ using an Optilux 500 halogen light (Demetron/Kerr, Danbury, CT, USA). Creation of resin composite build-ups was made using three $1.5 \mathrm{~mm}$ increments of Z100 resin composite (3M ESPE) that were individually light-cured for $20 \mathrm{~s}$ each.

Specimens in the dry bonded control group were not pretreated with GSE and had their wet dentin surfaces completely dried for $30 \mathrm{~s}$ with a continuous air blast at a distance of $10 \mathrm{~cm}$. They were then bonded with Single Bond Plus to dry dentin.

Specimens in the cross-linked wet bonded group were treated with various GSE primers for $60 \mathrm{~s}$, and were then rinsed for $10 \mathrm{~s}$ with the appropriate solvent (water, ethanol, or $5 \%$ ethanol/95\% water). They were then lightly blotted with a Kimwipe tissue (Fisher Scientific, Pittsburgh, PA, USA) moistened with the same solvent and immediately bonded as previously described.

Specimens in the cross-linked dry bonding group were treated with various GSE primers for $60 \mathrm{~s}$, rinsed with air-water spray for $10 \mathrm{~s}$ and then air-dried using full strength air from a 3-way syringe at a distance of $10 \mathrm{~cm}$ for $30 \mathrm{~s}$. They were then immediately dry bonded with Single Bond Plus and built up with resin composite as described above.

The resin-bonded teeth were immersed in labeled, separate containers in $37^{\circ} \mathrm{C}$ water for $24 \mathrm{~h}$. Then, using an Isomet saw with water cooling, the curved peripheries of each bonded tooth were cut away to yield a square bonded crown. The resulting "squared" crown was cut into $0.7 \mathrm{~mm}$ thick slabs. Each slab was, in turn, cut into $0.7 \mathrm{~mm}$ thick "sticks". The $\mu$ TBS of each stick was measured using Geraldeli testing jigs [35]. The tensile force at failure was recorded and divided by the cross-sectioned area of each stick, and expressed in MPa.

\subsection{Creation of dentin beams for 3-point flexure and hydroxyproline release}

One $0.5 \mathrm{~mm}$ thick dentin disk was obtained from each tooth using a Buehler diamond blade saw (Buehler Ltd.). Sixty dentin beams were cut from these disks that were $3 \mathrm{~mm}$ wide $\times 6 \mathrm{~mm}$ long, using the same saw. These beams were then completely demineralized in $10 \%$ phosphoric acid at $4{ }^{\circ} \mathrm{C}$ by tumbling in sealed containers for $18 \mathrm{~h}$. Complete demineralization was confirmed by measuring the modulus of elasticity of beams in water. A modulus of elasticity of $5 \mathrm{MPa}$ was considered as completely demineralized [36].

\subsection{Measurements of stiffness of completely demineralized dentin}

Due to the excellent $\mu$ TBS results obtained from using 5 mass $\%$ GSE in 5\% ethanol/95\% water, we decided to use this solvent alone for the remaining experimental procedures.

Thirty demineralized dentin beams were used to measure stiffness by 3-point flexure. The initial elastic modulus of each beam was determined by means of a testing machine (Vitrodyne 1000, Liveco Inc., Burlington, VA, USA) with a $1000 \mathrm{~g}$ load cell, at a crosshead speed of $1 \mathrm{~mm} / \mathrm{min}$. Load-displacement curves were converted to stress-strain curves, and modulus of elasticity $(E)$ was calculated at the steepest, most linear portion of the curve, using the formula $E=m L^{3} / 4 b d^{3}$, where $m=$ slope $(\mathrm{N} / \mathrm{mm}) ; \mathrm{L}=$ support span $(\mathrm{mm}) ; d=$ thickness of beam $(\mathrm{mm})$; $b=$ width of beam (mm). After initial baseline testing in water, beams (10/group) were placed into 5\% GSE in 5\% ethanol/95\% water for $1 \mathrm{~min}$ or $10 \mathrm{~min}$. Immediately following incubation stiffening, the beams were rinsed in water and re-tested under the same parameters, and the new stiffness was measured. Each beam served as its own control.

\subsection{Measurement of collagen solubilization by endogenous dentin proteases}

Previous work from our laboratory showed that when completely demineralized dentin beams were incubated in buffer at $37^{\circ} \mathrm{C}$, they lost dry mass and stiffness [31]. This loss of dry mass was associated with solubilization of hydroxyprolinecontaining collagen peptides. This hydrolytic activity is due to the presence of endogenous proteases in dentin matrices, including MMPs $-2,-8$, and -9 and cathepsin $\mathrm{K}[7,37]$. When these demineralized matrices were treated by cross-linking agents such as carbodiimide or glutaraldehyde, the loss of dry mass was significantly reduced $[22,23,38]$.

Thirty $3 \mathrm{~mm} \times 0.5 \mathrm{~mm} \times 6 \mathrm{~mm}$ dentin beams were prepared from mid-coronal dentin as described above. After rinsing in water, the demineralized beams (10/group) were dipped in water for $10 \mathrm{~min}$ or in $5 \mathrm{wt} \%$ GSE in 5\% ethanol/95\% water for $1 \mathrm{~min}$ or $10 \mathrm{~min}$, rinsed briefly and then dropped into $0.5 \mathrm{ml}$ of $0.05 \mathrm{M}$ HEPES buffer in sealed containers that were incubated at $37^{\circ} \mathrm{C}$ for 1 week with shaking at 15 cycles $/ \mathrm{min}$. The HEPES buffer ( $\mathrm{pH} 7.4$ ) also contained $2.5 \mathrm{mM} \mathrm{CaCl} 2 \cdot 2 \mathrm{H}_{2} \mathrm{O}$ and $0.02 \mathrm{mM} \mathrm{ZnCl}_{2}$ (both from Sigma-Aldrich, St. Louis, MO, USA). At the end of one week, $100 \mu \mathrm{L}$ of incubation media was mixed with an equal volume of $12 \mathrm{~N} \mathrm{HCl}$ to create $6 \mathrm{~N} \mathrm{HCl}$, which was used to hydrolyze the soluble collagen fragments into their 
constituent amino acids in sealed glass ampoules at $118^{\circ} \mathrm{C}$ for $16 \mathrm{~h}$. After opening vials, the $\mathrm{HCl}$ was allowed to evaporate in a vacuum dessicator, the bottom of which was covered by $\mathrm{NaOH}$ pellets to neutralize the $\mathrm{HCl}$. The dry residue was then analyzed for hydroxyproline using a colorimetric method [39].

\subsection{Scanning electron microscopy}

Control and experimental dentin specimens (3/group) were acid-etched with $37 \%$ phosphoric acid gel for $15 \mathrm{~s}$, then rinsed with water for $15 \mathrm{~s}$. The control specimens were then treated with water for $1 \mathrm{~min}$. The experimental teeth were treated with 5 mass\% GSE in water, ethanol or mixtures for $1 \mathrm{~min}$. All surfaces were rinsed with water for $15 \mathrm{~s}$ and then airdried for $30 \mathrm{~s}$ using continuous, full strength air for $30 \mathrm{~s}, 10 \mathrm{~cm}$ from the dentin surface. All specimens except those that were dry-bonded were critical-point dried (Samdri-790, Hummer Sputtering System, Anatech Corp., San Diego, CA, USA) prior to being coated with gold/palladium and examined in an SEM (Model XL-30 FEG, Philips Corp., Hillsboro, OR, USA) at $10 \mathrm{keV}$.

\subsection{Statistics}

The $\mu$ TBS obtained from beams derived from each of the 4 teeth in each group (8 groups) were pooled together to obtain the mean bond strength value. Each tooth was treated as a statistical unit. The bond strength data were analyzed via twoway ANOVA (SigmaPlot 13, Systat Software Inc., San Jose, CA, USA) using cross-linking as one factor and bonding type (wet us dry) as the second factor. There was a significant interaction between cross-linking and bond type $(p<0.001)$. Thus, the data were re-analyzed by the least squares means test. Least squares means are the expected value of group or subgroup means that one expects for a balanced design involving the group variable with all covariates at their mean value.

The matrix stiffness and collagen solubilization data were logarithmically transformed to obtain normal distribution and equality of variance. They were then analyzed using separate, one-way ANOVAs and Holm-Sidak multiple comparison tests (SigmaPlot 13). Statistical significance was set in advance at the 0.05 level.

\section{Results}

\subsection{Microtensile bond strengths}

When moist acid-etched, non-cross-linked dentin was treated with Single Bond Plus (wet-bonded control), the mean $\mu$ TBS was significantly higher than the non-crosslinked dry-bonded control group $(p<0.05$, Table 1$)$. Cross-linking moist acidetched dentin for $60 \mathrm{~s}$ with $5 \%$ GSE in all three solvents gave similar bond strengths that were not statistically different from the wet-bonded control group ( $p>0.05$, Table 1). Pretreating dentin with $5 \%$ GSE in water or ethanol and then air-drying for $30 \mathrm{~s}$, produced $\mu$ TBS values that were significantly lower $(p<0.05$, Table 1$)$ when compared to their wet-bonded values, although the $\mu$ TBS values were still significantly higher than the non-cross-linked dry control specimens. When acidetched dentin was cross-linked with 5\% GSE in 5\% ethanol/95\%
Table 1 - Comparison of wet vs dry bond strengths of dentin pretreated with different versions of GSE solvents and dentin bonded without GSE pretreatment (control).

\begin{tabular}{lcc} 
Groups & Wet bonding & Dry bonding \\
\hline Control & $53.5 \pm 3.6^{\mathrm{a}}$ & $9.4 \pm 1.8^{\mathrm{b}}$ \\
$5 \%$ GSE in water & $53.7 \pm 3.4^{\mathrm{a}}$ & $39.1 \pm 9.7^{\mathrm{c}}$ \\
$5 \%$ GSE in 100\% ethanol & $51.2 \pm 2.3^{\mathrm{a}}$ & $35.3 \pm 2.0^{\mathrm{c}}$ \\
$5 \%$ GSE in 5\% ethanol/95\% water & $53.0 \pm 2.3^{\mathrm{a}}$ & $55.7 \pm 5.1^{\mathrm{a}}$
\end{tabular}

$\dagger$ Values are mean \pm standard deviations, $n=4$ teeth. Means identified by different superscripts letters are statistically different (Holm-Sidak pairwise comparisons, $p<0.05$ ).

water and then air dried, there was no significant difference between its $\mu$ TBS values and those values derived from wetbonding ( $p>0.05$, Table 1$)$.

\subsection{Stiffness of completely demineralized dentin beams}

After immersion in 5\% GSE in 5\% ethanol/95\% water for $1 \mathrm{~min}$, the mean stiffness of demineralized dentin beams increased significantly when compared to the control value (Fig. 1). Increasing the incubation time to $10 \mathrm{~min}$ produced stiffness values that were higher than the 1 min beams $(p<0.05$, Fig. 1$)$.

\subsection{Collagen solubilization by endogenous dentin proteases}

Control beams incubated in HEPES buffer for 1 week released high levels of hydroxyproline-containing peptides into the incubation medium (Fig. 2). Beams pretreated with 5\% GSE in $5 \%$ ethanol/95\% water for 1 or 10 min released significantly lower hydroxyproline than the control values $(p<0.05)$. One minute of GSE incubation reduced collagen solubilization by

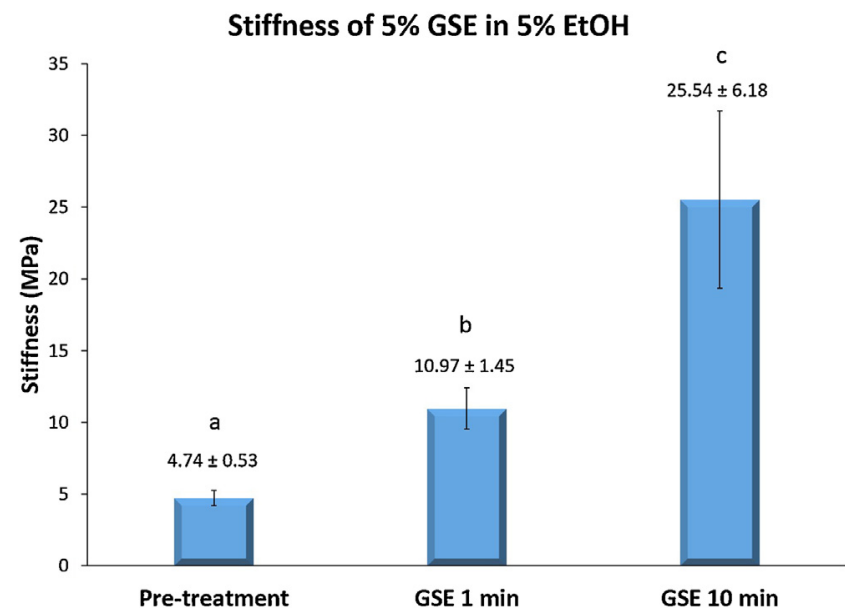

Fig. 1 - Modulus of elasticity of completely demineralized dentin beams subjected to 3-point flexure in water (control), and after 1 or 10 min immersion in 5 mass\% grape seed extract. Data are presented in means \pm standard deviations $(n=10)$. Groups identified by different lower case letters are significantly different (Holm-Sidak pairwise comparisons, $p<0.05$ ). 
Hydroxyproline Results from 5\% Grape Seed Extract

(GSE) treated beams after one week incubation in simulated body fluid

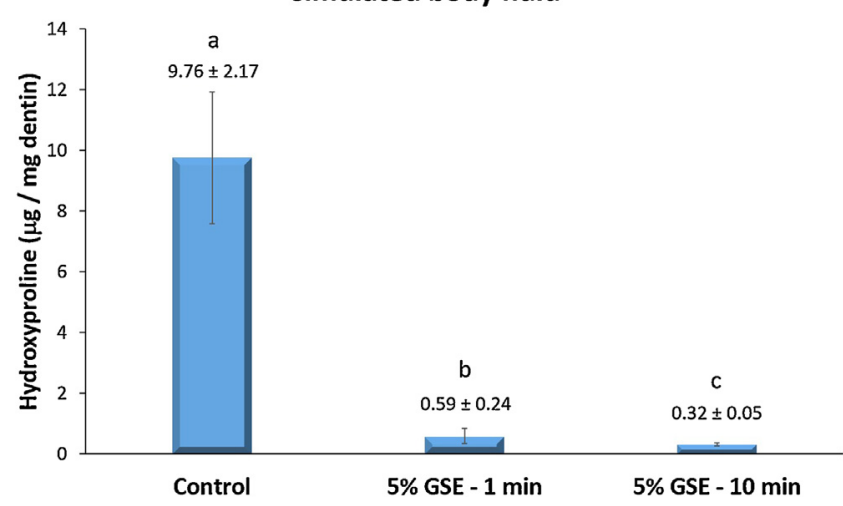

Fig. 2 - Release of hydroxyproline-containing soluble peptides from demineralized dentin (control) beams dipped in water for $10 \mathrm{~min}$ us beams dipped into $5 \mathrm{mass} \%$ GSE dissolved in $5 \%$ ethanol $/ 95 \%$ water for 1 or $10 \mathrm{~min}$, rinsed and then incubated in 0.05 M HEPES buffer ( $p H$ 7.4) for 1 week at $37^{\circ} \mathrm{C}$ with shaking. Heights of bars are the mean values of 10 beams per group. Brackets indicate \pm 1 SD. Groups identified by different lowercase letters are significantly different at $p<0.05$.

$94 \%$, while the reduction was $97 \%$ after $10 \mathrm{~min}$ (Fig. 2). These values were significantly different from each other.

\subsection{SEM of control us GSE-treated dentin}

Fig. 3 shows the image of a dentin surface that was acid-etched with $37 \%$ phosphoric acid for $15 \mathrm{~s}$, rinsed with water, and then critical-point dried to prevent collapse and fusion of collagen fibrils. The insert shows a higher magnification view of the acid-etched dentin surface that permits visualization of individual collagen fibrils separated from each other by interfibrillar spaces. These spaces serve as diffusion channels for inward adhesive monomer infiltration. At this magnification, the circumferential orientation of individual collagen fibrils lining the walls of the tubules can be clearly seen. This serves as a control for Fig. 4 which was treated similarly, but was allowed to be air dried for $30 \mathrm{~s}$.

Fig. 4 is a representative SEM image of dentin that was acidetched with $37 \%$ phosphoric acid for $15 \mathrm{~s}$, rinsed with water and then air-dried with a continuous maximum air blast for $30 \mathrm{~s}$ at a distance of $10 \mathrm{~cm}$. The intertubular dentin appeared to be smooth and amorphous. The tubules orifices have a "rolled-edge" appearance, unlike those seen in Fig. 3 where the orifices had sharp edges. No individual collagen fibrils can be seen between tubules. The "disappearance" of collagen fibrils was due to their fusion with each other by direct hydrogen bonding [2,7]. The intertubular dentin contains aggregates of fine granular material, representing silica that is added to the $37 \%$ phosphoric acid liquid to control the rheology of the gel etchant.

Fig. 5 is an image of acid-etched dentin that was treated with 5 mass $\%$ grape seed extract dissolved in $5 \%$ ethanol/95\% water for $60 \mathrm{~s}$ and then rinsed with water for $10 \mathrm{~s}$ before $30 \mathrm{~s}$ of

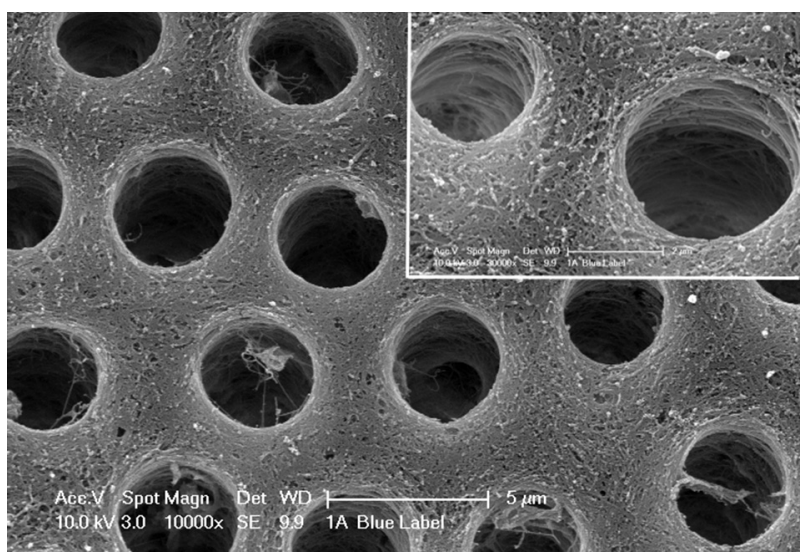

Fig. 3 - Scanning electron microscopy images of a mid-coronal crown dentin surface that was acid-etched with $37 \%$ phosphoric acid for $15 \mathrm{~s}$ and then rinsed with water for $10 \mathrm{~s}$ before being processed by critical-point drying $(10,000 x)$. Note the lack of peritubular dentin and the presence of individual collagen fibrils in the intertubular dentin and individual circumferential collagen fibrils within the dentinal tubules. INSERT. A higher magnification view of the same specimen $(30,000 x)$. Interfibrillar spaces could be identified between both the collagen fibrils in the intertubular dentin, and within the circumferential collagen fibrils with the lining of the tubules.

air drying. The texture of the intertubular dentin is not smooth and amorphous, but is rough. The circumferentially oriented collagen fibrils lining the tubules are well-separated, revealing interfibrillar spaces.

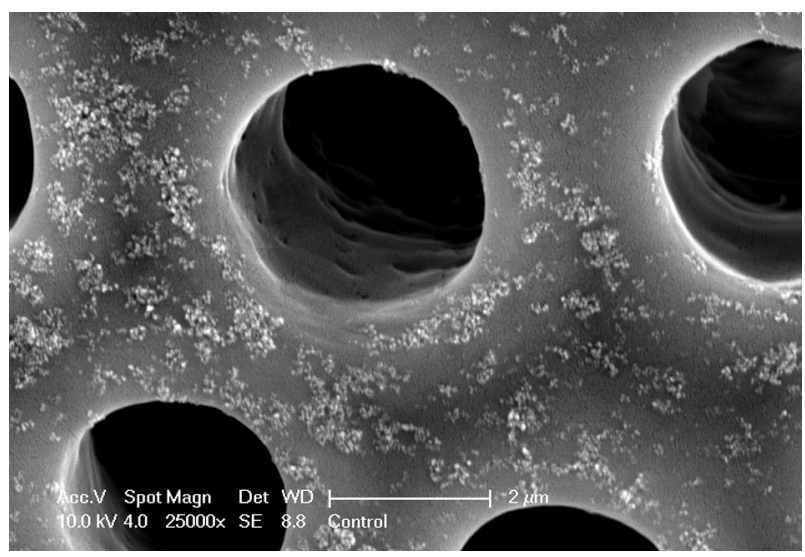

Fig. 4 - Scanning electron microscopy image of a mid-coronal crown dentin that was acid-etched for $15 \mathrm{~s}$ with $37 \%$ phosphoric acid, rinsed with water for $10 \mathrm{~s}$ and then air-dried for $30 \mathrm{~s}$ with continuous air blast at a distance of $10 \mathrm{~cm}(25,000 \mathrm{x})$. Fine granular materials present on the surface of the collapsed intertubular dentin are silica gel used by $3 \mathrm{M}$ to gel their phosphoric acid etchant. No individual collagen fibrils could be identified on the surface of the intertubular dentin or within the walls of the dentinal tubules because they have fused with each other by direct hydrogen bonding [7]. 


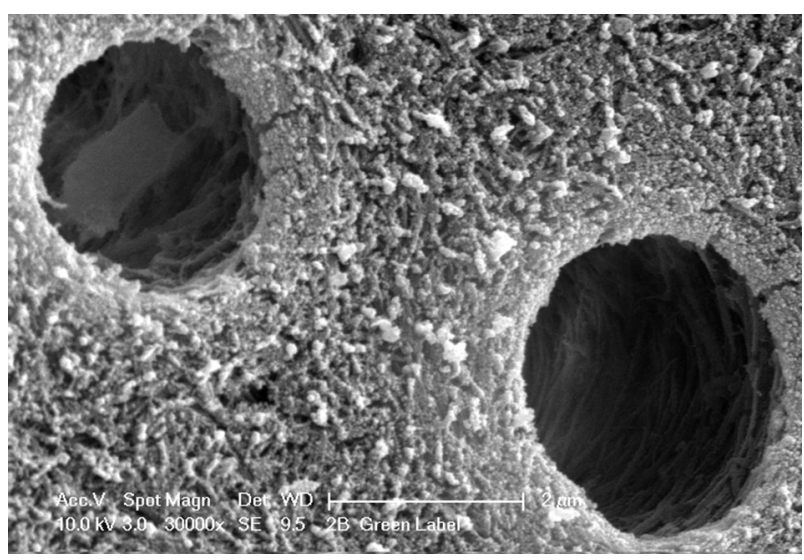

Fig. 5 - Scanning electron microscopy image of a mid-coronal crown dentin that was acid-etched for $15 \mathrm{~s}$ with $37 \%$ phosphoric acid and rinsed with water for $10 \mathrm{~s}$. The acid-etched dentin surface was then treated with 5 mass $\%$ grape seed extract dissolved in 5\% ethanol/95\% water for $60 \mathrm{~s}$, followed by rinsing for $10 \mathrm{~s}$ with water and air drying for $30 \mathrm{~s}$ with air blast. $(30,000 \mathrm{x})$. The intertubular dentin has a rough surface texture in which individual collagen fibrils can be recognized between the tubules and within tubules. Unlike the control in Fig. 4, the collagen fibrils in this figure did not collapse or fuse with each other.

\section{Discussion}

Because the $\mu$ TBS value of non-cross-linked wet-bonded dentin was $53.5 \pm 3.6 \mathrm{MPa}$, while that of non-cross-linked drybonded dentin was only $9.4 \pm 1.8 \mathrm{MPa}(p<0.05)$, the results require rejection of the first null hypothesis. We speculate that non-cross-linked, dry-bonded specimens that were devoid of interfibrillar spaces did not permit resin-infiltration through the collapsed, air-dried surface [7]. We speculate that the low bond strengths were due largely to the presence of unhybridized resin tags in the tubules that are known to only contribute about $10 \mathrm{MPa}$ to total bond strength [40].

Microtensile bond strengths of control, non-cross-linked dentin bonded using the wet bonding technique and specimens pretreated with 5 mass\% GSE in all solvents under wet conditions were over $50 \mathrm{MPa}$, while those made to GSE in $100 \%$ water or ethanol under dry conditions were less than $40 \mathrm{MPa}$ (Table 1). Cross-linked specimens pretreated with GSE in $5 \%$ ethanol/95\% water gave high bond strengths to dentin under both wet and dry conditions. These data require partial rejection of the second null hypothesis.

Because there was no significant difference between the $\mu$ TBS values of control wet-bonded dentin $(53.5 \pm 3.6 \mathrm{MPa})$ and GSE-cross-linked wet-bonded dentin (51-53 MPa, Table 1), the third null hypothesis cannot be rejected.

In the present study, GSE was used to cross-link and stiffen acid-etched dentin. Grape seed extract is a complex mixture of polyphenol monomers, dimers, trimers, tetramers, and polymers [41]. This cross-linking agent, while very effective, has a brown color that might prevent its use in esthetic dentistry. However, we also used 1.0 mass\% GSE and obtained $\mu$ TBS values that were as high as those produced by 5.0 mass $\%$ GSE, but had a much paler color than did the $5 \%$ solutions (data not shown). The use of GSE as a cross-linker is meant to be illustrative of results that may be achieved using cross-linking materials in general. The results obtained in the present study using GSE need to be confirmed in similar studies using glutaraldehyde or carbodiimide or other cross-linking agents. We speculate that by removing unbound water from acidetched, cross-linked dentin matrices by $30 \mathrm{~s}$ of air-drying, more hydrophobic resin formulations free of HEMA and rich in dimethacrylates may be used to infiltrate the collagen matrix of dentin, without inducing the phase separations of dimethacrylates that are seen in water-wet bonding $[14,15]$. We demonstrated that BisGMA alone could be used to infiltrate acid-etched dentin using the ethanol-wet bonding technique to remove residual water [28]. This should also be possible using the cross-linking, dry bonding technique.

Pretreatment of acid-etched dentin matrices with crosslinking agents is known to inactivate the endogenous proteases of dentin $[23,37]$ that are hydrolases. Cross-linking also prevents collagenases from unwinding the collagen triple helix that is necessary for collagenases to cleave all three polypeptides in the tropocollagen molecule $[5,42,43]$. In the absence of water, the cross-linked collagen can be infiltrated with dimethacrylates such as TEGDMA and BisGMA that are known to absorb little water [17], thereby extending the durability of resin-dentin bonds, one of the goals of the NIDCR's current research emphases. As resin-dentin formulations become more hydrophobic, they adsorb much less water than current hydrophilic formulations [17], reducing their tendency to become plasticized by water over time.

One possible explanation for GSE treatment preventing complete collapse of acid-etched dentin collagen fibrils is that the GSE becomes bound to collagen fibrils. Periodic binding may hold the fibrils apart, leaving sufficient room for resin infiltration. Alternatively, the collagen fibrils stiffness may have prevented the fibrils from complete collapse [22,23].

Clearly, non-cross-linked collagen fibrils collapsed completely when air-dried. There were no spaces between the collagen fibrils because, in the absence of water, they hydrogen bonded to each other [2]. Interfibrillar spaces between collagen fibrils serve as diffusion channels for resin monomer infiltration. Without interfibrillar spaces, resin infiltration of surface collagen fibrils will be incomplete. Additionally, lack of interfibrillar spaces in dentinal tubules results in loose resin tags that are not anchored to the surrounding intertubular dentin. The result is a $\mu \mathrm{TBS}$ of about $10 \mathrm{MPa}$ that is insufficient to oppose the forces of polymerization contraction [44].

When acid-etched dentin was cross-linked with 5\% GSE for $60 \mathrm{~s}$ prior to air-drying, the collagen fibrils did not collapse upon themselves and fuse together, as was seen in the noncross-linked demineralized matrices when they were air-dried (compare Fig. 4 us Fig. 5). Although 5\% GSE in 5\% ethanol/95\% water cross-linked demineralized matrices did shrink some when air-dried, they left sufficient interfibrillar space to create $\mu$ TBS values $(55.7 \pm 5.1 \mathrm{MPa})$ that were not different from wet bonded controls. Little is known regarding how much interfibrillar space is required for achieving optimal bond strength. Apparently, treatment of acid-etched dentin with 5\% GSE in 5\% ethanol/95 water prior to air-drying provides sufficient interfibrillar spaces to achieve $\mu \mathrm{TBS}$ of $55 \mathrm{MPa}$ (Table 1 ). 
An alternate explanation is that the polyphenols bind to dentin non-uniformly. When the polyphenol-coated collagen fibrils are air-dried, we speculate that the polyphenols hydrogen bond to their nearest neighbors, stiffening the matrix enough so that it does not collapse completely, but leaves sufficient interfibrillar spaces for resin infiltration.

The clear superiority of 5\% ethanol/95\% water as a GSE solvent for producing higher $\mu$ TBS than either $5 \%$ GSE in $100 \%$ ethanol or in $100 \%$ water, requires more research. As GSE is a mixture of polyphenols, $5 \%$ ethanol/95\% water may solubilize more of the larger oligomers [32] that contain additional hydroxyl groups that could provide more covalent and noncovalent bonds [32,45].

Three-point flexure of completely demineralized beams revealed that $10 \mathrm{~min}$ exposure to 5 mass $\%$ GSE extract increased the stiffness from $4.74 \pm 0.53 \mathrm{MPa}$ to $25.54 \pm 6.18 \mathrm{MPa}$ (Fig. 1). As the macrohybrid layer [2] specimens used in the 3-point flexure experiments were $0.5 \mathrm{~mm}$ thick beams, their thickness $(500 \mu \mathrm{m})$ was 50 times thicker than acid-etched demineralized layers in resin-dentin bonds (10 $\mu \mathrm{m}$ thick). Thus, it is likely that the $10 \mu \mathrm{m}$ demineralized matrix surfaces that are created clinically can become cross-linked much faster than the $500 \mu \mathrm{m}$-thick beams. Direct extrapolations between $10 \mu \mathrm{m}$ demineralized layers to $0.5 \mathrm{~mm}$-thick beams is fraught with risk, but it is clear that $1 \mathrm{~min}$ of $5 \%$ GSE in $5 \%$ ethanol/95\% water treatment of an acid-etched layer probably stiffens the collagen fibrils far above their $4.74 \mathrm{MPa}$ control values. That increase in stiffness may have prevented the complete collapse of collagen fibrils that was seen in the control SEM (Fig. 4) after air-drying.

The combination of cross-linking acid-etched dentin and dry-bonding needs to be tested with other cross-linking agents. The ability to remove water before it has been mixed with solvated adhesives permits more rapid water evaporation because the water vapor of pure water at $37^{\circ} \mathrm{C}$ is $47 \mathrm{~mm} \mathrm{Hg}$. When solvated resin monomers are added, the vapor pressure of water can fall significantly $[27,46]$, making it harder to evaporate solvents, including water, from dentin. Strong continuous air blasts for $30 \mathrm{~s}$ physically force much of the water from the matrix and then evaporate the residual water. By removing most of the free water, one reduces the risk of the phase changes that can occur when solvated dimethacrylates are mixed with water-saturated dentin. We speculate that in the absence of free water, there should be no portions of hybrid layers infiltrated with residual water instead of resin, and the endogenous hydrolases of the dentin matrix (i.e. MMPs and cathepsins) should be unable to cleave collagen. As residual water decreases, resin formulations containing more dimethacrylates can be utilized. The present study needs to be repeated using more hydrophobic resins $[2,17,47]$. Furthermore, these results need to be confirmed under in vivo conditions. The many advantages of cross-linked dry bonding need to be explored further and fully optimized before it can become a routine bonding practice.

\section{Conclusion}

This work is dedicated to the pioneering work of Professor Fusayama [48] who had the correct idea, but did not know that air-drying completely collapsed collagen fibrils, or how to avoid that collapse. The results of the present work demonstrate the proof-of-concept that acid-etched dentin stiffened by 60 s by $5 \%$ GSE in $5 \%$ ethanol/95\% water cross-linking prior to air drying, does not restrict resin uptake enough to lower bond strengths below wet-bonding levels. We speculate that cross-linking, dry-bonding should permit the infiltration of water-free, dimethacrylate-rich, relatively hydrophobic resin monomer blends into such matrices, that should create strong resin-dentin bonds to dentin. Five percent GSE in 5\% ethanol/95\% water inactivated the endogenous proteases of dentin, and should increase the durability of the bonds. Future long-term experiments on nanoleakage and bond strength over time should test those hypotheses. The final test of such techniques is to determine if clinicians can achieve more durable, resin-dentin bonds under in vivo conditions.

\section{Conflict of interest}

None of the authors received payment from any manufacturers to support this work.

\section{Acknowledgements}

This work was supported, in part, by grant R01 DE015306 from the NIDCR (PI: David H. Pashley). The authors are grateful to 3M ESPE (St. Paul, MN, USA) for generous donations of Single Bond Plus and $\mathrm{Z100}$ resin composites. We recognize the support from FAPESP (2014/18160-7 and 2014/17232-4). This work was supported, in part, by King Abdulaziz University to DHP as a HiCi scholar. The authors thank Mrs. Michelle Barnes for her secretarial support.

\section{REFERENCES}

[1] Barton AF. Handbook of solubility parameters and other cohesion parameter. Boca Raton: CRC Press; 1991. p. 137.

[2] Pashley DH, Tay FR, Carvalho RM, Rueggeberg FA, Agee KA, Carrilho M, et al. From dry bonding to water-wet bonding to ethanol wet-bonding. A review of the interactions between dentin matrix and solvated resins using a macromodel of the hybrid layer. Am J Dent 2007;20:7-20.

[3] Pashley DH, Agee KA, Nakajima M, Tay FR, Carvalho RM, Terada R, et al. Solvent-induced dimensional changes in EDTA-demineralized dentin matrix. J Biomed Mater Res 2001;56:273-81.

[4] Pashley DH, Agee KA, Carvalho RM, Lee KW, Tay FR, Callison TE. Effects of water and water-free polar solvents on the tensile properties of demineralized dentin. Dent Mater 2003;19:347-52.

[5] Dielmann-Geener J, Grossman M, Conti Nibali V, Born B, Solomonov I, Fields GB, et al. Enzymatic turnover of macromolecules generates long-lasting protein-water-coupled motions beyond reaction steady state. Proc Natl Acad Sci U S A 2014;111:17857-62.

[6] Ryou H, Niu LN, Dai L, Pucci CR, Arola DD, Pashley DH, et al. Effect of biomimetic remineralization on the dynamic nanomechanical properties of dentin hybrid layers. J Dent Res 2011;90:1122-8. 
[7] Pashley DH, Tay FR, Breschi L, Tjäderhane L, Carvalho RM, Carrilho M, et al. State of the art of etch-and-rinse adhesives. Dent Mater 2011;27:1-16.

[8] Pashley DH, Ciucchi B, Sano H, Horner JA. Permeability of dentin to adhesive agents. Quintessence Int 1993;24: 618-31.

[9] Kanca J. A method for bonding to tooth structure using phosphoric acid as a dentin-enamel conditioner. Quintessence Int 1991;22:285-90.

[10] Kanca J. Effect of resin primer solvents and surface wetness on resin composite bond strength to dentin. Am J Dent 1992;5:213-5.

[11] Kanca J. Improving bond strength through acid etching of dentin and bonding to wet dentin surfaces. J Am Dent Assoc 1992;123:35-43.

[12] Brackett MG, Li N, Brackett WW, Sword RJ, Qi YP, Niu LN, et al. The critical barrier to progress in dentine bonding with the etch-and-rinse technique. J Dent 2011;39: 238-48.

[13] Abedin F, Ye Q, Parthasarathy R, Misra A, Spencer P. Polymerization behavior of hydrophilic-rich phase of dentin adhesive. J Dent Res 2015;94:500-7.

[14] Spencer P, Wang Y. Adhesive phase separation at the dentin interface under wet bonding conditions. J Biomed Mater Res 2002;62:447-56.

[15] Ye Q Park JG, Topp E, Wang Y, Misra A, Spencer P. In vitro performance of nano-heterogeneous dentin adhesive. J Dent Res 2008;87:829-33.

[16] Ye Q, Wang Y, Spencer P. Nanophase separation of polymers exposed to simulated bonding conditions. J Biomed Mater Res Part B Appl Biomater 2009;88:339-48.

[17] Ito S, Hashimoto M, Wadgaonkar B, Svizero N, Carvalho RM, Yiu C, et al. Effects of resin hydrophilicity on water sorption and changes in modulus of elasticity. Biomaterials 2005;26:6449-59.

[18] Bedran-Russo AK, Castellan CS, Shinohara MS, Hassan L, Antunes A. Characterization of biomodified dentin matrices for potential preventive and reparative therapies. Acta Biomater 2011;7:1735-41.

[19] Liu Y, Dusevich V, Wang Y. Proanthocyanidins rapidly stabilize the demineralized dentin layer. J Dent Res 2013;92:746-52.

[20] Liu Y, Dusevich V, Wang Y. Addition of grape seed extract renders phosphoric acid a collagen-stabilizing etchant. J Dent Res 2014;93:821-7.

[21] Bedran-Russo AK, Pashley DH, Agee K, Drummond JL, Miescke J. Changes in stiffness of demineralized dentin following application of collagen crosslinkers. J Biomed Mater Res Part B Appl Biomater 2008;86:330-4.

[22] Scheffel DL, Hebling J, Scheffel RH, Agee K, Turco G, de Souza Costa CA, et al. Inactivation of matrix-bound matrix metalloproteinases by cross-linking agents in acid-etched dentin. Oper Dent 2014;39:152-8.

[23] Scheffel DL, Hebling J, Scheffel RH, Agee KA, Cadenaro M, Turco G, et al. Stabilization of dentin matrix after cross-linking treatments, in vitro. Dent Mater 2014;30:227-33.

[24] Ito S, Saito T, Tay FR, Carvalho RM, Yoshiyama M, Pashley DH. Water content and apparent stiffness of noncarious versus caries-affected human dentin. J Biomed Mater Res Part B Appl Biomater 2005;72:109-16.

[25] Eddleston CL, Hindle AR, Agee KA, Carvalho RM, Tay FR, Rueggeberg FA, et al. Dimensional changes in acid-demineralized dentin matrices following the use of HEMA-water versus HEMA-alcohol primers. J Biomed Mater Res 2003;67A:900-7.

[26] Weast RC. Handbook of chemistry and physics. Cleveland, OH: The Chemical Rubber Company; 1971.
[27] Pashley EL, Zhang Y, Lockwood PE, Rueggeberg FA, Pashley DH. Effects of HEMA on water evaporation from water-HEMA mixtures. Dent Mater 1998;14:6-10.

[28] Tay FR, Pashley DH, Kapur RR, Carrilho MR, Hur YB, Garrett $\mathrm{LV}$, et al. Bonding BisGMA to dentin - proof of concept for hydrophobic dentin bonding. J Dent Res 2007;86:1034-9.

[29] Sadek FT, Pashley DH, Nishitani Y, Carrilho MR, Donnelly A, Ferrari M, et al. Application of hydrophobic resin adhesives to acid-etched dentin with an alternative wet bonding technique. J Biomed Mater Res A 2008;84:19-29.

[30] Sadek FT, Braga RR, Muench A, Liu Y, Pashley DH, Tay FR. Ethanol wet-bonding challenges current anti-degradation strategy. J Dent Res 2010;89:1499-504.

[31] Sadek FR, Castellan CS, Braga RR, Mai S, Tjäderhane L, Pashley DH, et al. One-year stability of resin-dentin bonds created with a hydrophobic ethanol-wet bonding technique. Dent Mater 2010;26:380-6.

[32] Aguiar TR, Vidal CM, Phansalkar RS, Todorova I, Napotilano JG, McAlpine JB, et al. Dentin biomodification potential depends on polyphenol source. J Dent Res 2014;93:417-22.

[33] Tay FR, Sano H, Carvalho R, Pashley EL, Pashley DH. An ultrastructural study of the influence of acidity of self-etching primers and smear layer thickness on bonding to intact dentin. J Adhes Dent 2000;2:83-98.

[34] Koibuchi H, Yasuda N, Nakabayashi N. Bonding to dentin with a self-etching primer: the effect of smear layers. Dent Mater 2001;17:122-6.

[35] Perdigão J, Geraldeli S, Carmo AR, Dutra HR. In vivo influence of residual moisture on microtensile bond strengths of one-bottle adhesives. J Esthet Restor Dent 2002;14:31-8.

[36] Carrilho MR, Tay FR, Donnelly AM, Agee KA, Tjäderhane L, Mazzoni A, et al. Host-derived loss of dentin matrix stiffness associated with solubilization of collagen. J Biomed Mater Res B Appl Biomater 2009;90:373-80.

[37] Tjäderhane L, Nascimento FD, Breschi L, Mazzoni A, Tersariol IL, Geraldeli S, et al. Strategies to prevent hydrolytic degradation of the hybrid layers - a review. Dent Mater 2013;29:999-1011.

[38] Tezvergil-Mutluay A, Mutluay MM, Agee KA, Seseogullari-Dirihan R, Hoshika T, Cadenaro M, et al. Carbodiimide cross-linking inactivates soluble and matrix-bound MMPs, in vitro. J Dent Res 2012;91:192-6.

[39] Jamall IS, Finelli VN, Queltee SS. A simple method to determine nanogram levels of 4-hydroxyproline in biological tissue. Anal Biochem 1981;112:70-5.

[40] Pashley DH, Ciucchi B, Sano H, Carvalho RM, Russell CM. Bond strength versus dentine structure: a modelling approach. Arch Oral Biol 1995;40:1109-18.

[41] Nam JW, Phansalkar RS, Lankin DC, Bisson J, McAlpine JB, Leme AA, et al. Subtle chemical shifts explain the NMR fingerprints of oligomeric proanthocyanidins with high dentin biomodification potency. J Org Chem 2015;80:7495-507.

[42] Perumal S, Antipova O, Orgel PRO. Collagen fibril architecture, domain organization, and triple-helical confirmation governs its proteolysis. Proc Natl Acad Sci U S A 2008;105:2824-9.

[43] Chung L, Dinakarpandian D, Yoshida N, Lauer-Fields JL, Fields GB, Visse R, et al. Collagenase unwinds triple-helical collagen prior to peptide bond hydrolysis. EMBO J 2004;23:3020-30.

[44] Davidson CL, deGee AJ, Feilzer A. The competition between the composite-dentin bond strength and the polymerization contraction stress. J Dent Res 1984;63:1396-9.

[45] Bedran-Russo AK, Pauli GF, Chen SN, McAlpine J, Castellan CS, Phansalkar RS, et al. Dentin biomodification: strategies, renewable resources and clinical applications. Dent Mater 2014;30:62-76. 
[46] Cadenaro M, Breschi L, Rueggeberg FA, Suchko M, Grodin E, Agee $\mathrm{K}$, et al. Effects of residual ethanol on the rate and degree of conversion of five experimental resins. Dent Mater 2009;25:621-8.

[47] Talungchit S, Jessop JLP, Cobb DS, Qian F, Geraldeli S, Pashley $\mathrm{DH}$, et al. Ethanol-wet bonding and chlorhexidine improve resin-dentin bond durability: quantitative analysis using Raman spectroscopy. J Adhes Dent 2014;16:441-50.

[48] Fusayama T. New concepts in operative dentistry. Chicago, IL: Quintessence Publishing Co., Inc.; 1980. 